\title{
Surgical Outcomes According to Dekyphosis in Patients with Ossification of the Posterior Longitudinal Ligament in the Thoracic Spine
}

\author{
Soo Yeon Kim, Seung-Jae Hyun, Ki-Jeong Kim, Tae-Ahn Jahng, Hyun-Jib Kim \\ Department of Neurosurgery, Spine Center, Seoul National University Bundang Hospital, Seoul National University College of Medicine, \\ Seongnam, Korea
}

Objective : Ossification of posterior longitudinal ligament (OPLL) in the thoracic spine may cause chronic compressive myelopathy that is usually progressive, and unfavorable by conservative treatment. Although surgical intervention is often needed, the standard surgical method has not been established. Recently, it has been reported that posterior decompression with dekyphosis is effective surgical technique for favorable clinical outcome. The purpose of this study was to evaluate the surgical outcomes in patients with thoracic OPLL according to dekyphosis procedure and to identify predictive factors for the surgical results.

Methods : A total of 25 patients with thoracic OPLL who underwent surgery for myelopathy from May 2004 to March 2017, were retrospectively reviewed. Patients with cervical myelopathy were excluded. We assessed the clinical outcomes according to various surgical approaches. The modified Japanese orthopedic association (JOA) scores for the thoracic spine (total, 11 points) and JOA recovery rates were used for investigating surgical outcomes.

Results : Of the 25 patients, 10 patients were male and the others were female. The mean JOA score was $6.7 \pm 2.3$ points preoperatively and $8.8 \pm 1.8$ points postoperatively, yielding a mean recovery rate of $53.8 \pm 31.0 \%$. The mean patients' age at surgery was 52.4 years and mean follow-up period was 40.2 months. According to surgical approaches, seven patients underwent anterior approaches, 13 patients underwent posterior approaches, five patients underwent combined approaches. There was no significant difference of the surgical outcomes related with different surgical approaches. Age ( $\geq 55$ years) and high signal intensity on preoperative magnetic resonance (MR) image in the thoracic spine were significant predictors of the lower recovery rate after surgery $(p<0.05)$. Posterior decompression with dekyphosis procedure was related to the excellent surgical outcomes $(p=0.047)$. Dekyphosis did not affect the complication rates.

Conclusion : In this study, our result elucidated that old age ( $\geq 55$ years) and presence of intramedullary high signal intensity on preoperative MR images were risk factors related to poor surgical outcomes. In the meanwhile, posterior decompression with dekyphosis affected favorable clinical outcome. Posterior approach with dekyphosis procedure can be a recommendable surgical option for favorable results.

Key Words : Ossification of posterior longitudinal ligament · Thoracic vertebrae $\cdot$ Kyphosis · Treatment outcome.

- Received : September 3, 2018 •Revised : October 23, 2018 •Accepted : November 26, 2018

- Address for reprints : Seung-Jae Hyun

Department of Neurosurgery, Spine Center, Seoul National University Bundang Hospital, Seoul National University College of Medicine, 82 Gumi-ro 173beon-gil, Bundang-gu, Seongnam 13620, Korea

Tel : +82-31-787-7169, Fax : +82-31-787-4097, E-mail : hyunsj@snu.ac.kr, ORCID : https://orcid.org/0000-0003-2937-5300

This is an Open Access article distributed under the terms of the Creative Commons Attribution Non-Commercial License (http://creativecommons.org/licenses/by-nc/4.0) which permits unrestricted non-commercial use, distribution, and reproduction in any medium, provided the original work is properly cited. 


\section{INTRODUCTION}

Ossification of posterior longitudinal ligament (OPLL) in the thoracic spine is rare condition compared with cervical OPLL depending on the previous reports ${ }^{4,17,20,21,23)}$. For this reason, characteristics of thoracic OPLL have not been adequately addressed.

Thoracic OPLL often produces chronic compressive myelopathy that is usually progressive and unfavorable by conservative treatment. Therefore, surgical intervention is usually needed, surgical technique and decision making are also important. This is because of the high risk of complication related with surgery ${ }^{19}$. Different results of various surgical approaches and techniques have been reported ${ }^{2,8,13-15,25)}$. Posterior approach is considered to be relatively safe, although definitive results of an optimal surgical method have not been presented. Recently, it has been reported that posterior approach with kyphosis correction is effective surgical method for decompression through posterior migration of the spinal $\operatorname{cord}^{27}$. We performed the surgery mainly through the posterior approaches, and we focused on the effect of dekyphosis procedure for treating thoracic OPLL.

The purpose of this study was to evaluate the surgical outcomes in patients with thoracic OPLL according to dekyphosis procedure and to investigate the predictive factors for the surgical outcomes.

\section{MATERIALS AND METHODS}

This report was approved by Institutional Review Board (IRB No. : B-1911-577-109). Between May 2004 and March 2017, 25 patients, who underwent surgery for thoracic myelopathy due to OPLL, included in this study. The patients with cervical myelopathy were excluded. They were observed for a minimum of 1 year postoperatively. We evaluated the severity of patients' myelopathy before and after surgery using the Japanese Orthopedic Association (JOA) scores for the thoracic spine (total, 11 points), which was derived from the JOA scoring system for cervical myelopathy by eliminating the motor and sensory scores for the upper extremities (Table 1). In addition, surgical outcomes was evaluated with JOA recovery rate that were calculated by the following formula : (postoperative JOA score - preoperative JOA score) / (11 - preoperative JOA score) $\times 100 \%$.

The JOA scores were checked before surgery, a week, 3 months, 1 year after the surgery, and at the final follow-up visit. Recovery rates were calculated by comparing the final follow-up JOA score with the preoperative JOA score.

The mainly affected lesions were classified as upper (T1T4), middle (T5-T8), or lower lesions (T9-T12) on the basis of the level of thoracic spine where they exert maximum compression on $\mathrm{T} 2$ weighted sagittal magnetic resonance (MR) image. We also noted presence of intramedullary high signal intensity on T2 weighted MR images in the thoracic spine, except for two unidentifiable images from outside. Ossification size was defined as an antero-posterior length of OPLL in the axial computed tomography (CT) image of the maximal compression level. Degree of cord compression was computed OPLL length divided by spinal diameter. Morphology of

Table 1. Summary of angiographic and clinical outcomes

\begin{tabular}{|c|c|}
\hline Category & $\begin{array}{l}\text { Score } \\
\text { (points) }\end{array}$ \\
\hline \multicolumn{2}{|l|}{ A. Lower extremity motor function } \\
\hline Unable to stand up and walk by any means & 0 \\
\hline $\begin{array}{l}\text { Unable to walk without a cane or other support on a } \\
\text { level }\end{array}$ & 1 \\
\hline $\begin{array}{l}\text { Walks independently on a level but needs support on } \\
\text { stairs }\end{array}$ & 2 \\
\hline Capable of fast walking but clumsy & 3 \\
\hline Normal & 4 \\
\hline \multicolumn{2}{|l|}{ B. Sensory function } \\
\hline \multicolumn{2}{|l|}{ I. Lower extremity } \\
\hline Apparent sensory loss & 0 \\
\hline Minimal sensory loss & 1 \\
\hline Normal & 2 \\
\hline \multicolumn{2}{|l|}{ II. Trunk } \\
\hline Apparent sensory loss & 0 \\
\hline Minimal sensory loss & 1 \\
\hline Normal & 2 \\
\hline \multicolumn{2}{|l|}{ C. Bladder function } \\
\hline Urinary retention and/or incontinence & 0 \\
\hline Sense of retention and/or dribbling and/or thin stream & 1 \\
\hline Urinary retardation and/or pollakisuria & 2 \\
\hline Normal & 3 \\
\hline Total score for normal patient & 11 \\
\hline
\end{tabular}

JOA : Japanese Orthopedic Association 
OPLL was classified into three types (flat, beak, or mixed) according to previous reports ${ }^{1,18}$.

Surgical treatment was performed by four attending neurosurgeons. They evaluated the clinical and radiological status of the patients and selected the surgical method based on their consent. There were cases in which kyphosis correction was attempted. At first, dekyphosis was performed through intraoperative positioning using Jackson spine table. In addition, further dekyphosis was achieved by surgical facetectomy/posterior column osteotomies and in site bending after rod installation (Fig. 1). Dekyphosis was defined as the decrease of Cobb's angle after surgery based on fused thoracic spinal segments.

Intraoperative and postoperative complications were reviewed. Motor deterioration was defined as more one grade worsening of motor power rather than preoperative condition using the criteria of Medical research council scale.

Data were analyzed using the SPSS version 24 software (IBM Corp., New York, NY, USA). Statistical analysis was performed by student's t-test and one way analysis of variance for comparing with surgical outcome according to patients' factors and surgical approaches. Fisher's exact test is used for evaluation of complication rates. A $p$-value of less than 0.05 was considered statistically significant.

\section{RESULTS}

\section{Demographics}

The mean patients' age at surgery was $52.4 \pm 11.0$ years and mean follow-up period was $40.2 \pm 26.6$ months. The mean JOA score was $6.7 \pm 2.3$ points preoperatively and $8.8 \pm 1.8$ points postoperatively, yielding a mean recovery rate of $53.8 \pm 31.0 \%$. Duration of symptoms before surgery was $18.7 \pm 32.5$ months, and nine patients (36\%) had cervical OPLL history. Patients with old age ( $\geq 55$ years) were related to poor recovery rate ( $p=0.015$, Table 2$)$.

\section{Surgical outcomes related with radiological fea- tures}

In the radiological exam, ossification of ligamentum flavum was detected in 14 patients (56\%), intramedullary high signal intensity in preoperative MR image in 17 patients (68\%), and lesions that limited single-level in 10 patients (40\%). Patients with intramedullary high signal intensity on preoperative MR image showed significantly lower preoperative, postoperative JOA scores and recovery rate than patients without that $(p=0.048)$. Patients who limited single-level lesions had higher preoperative and postoperative JOA scores than patients with multiple-segment lesions, but difference of recovery rate was not significant between two groups. Patients
(A)

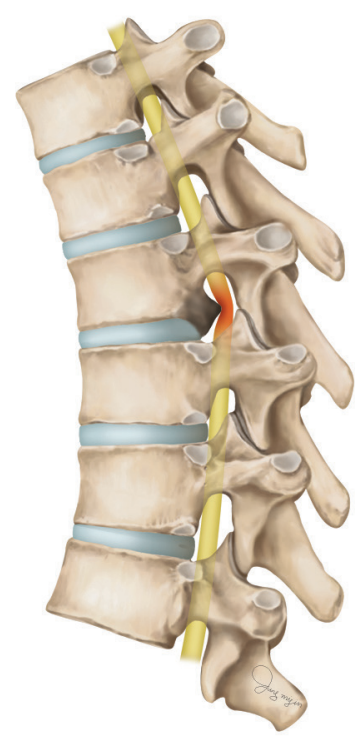

(B)

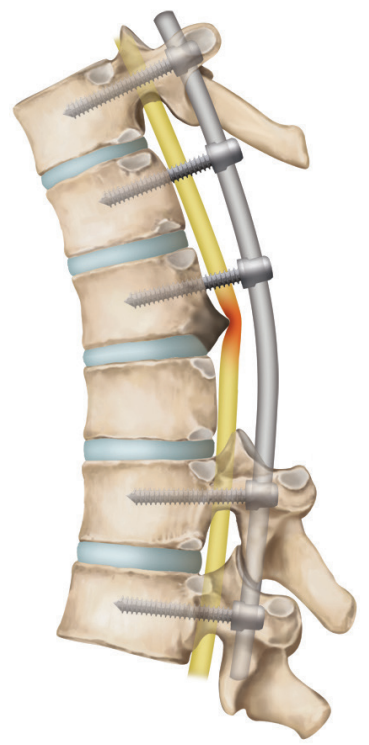

(C)

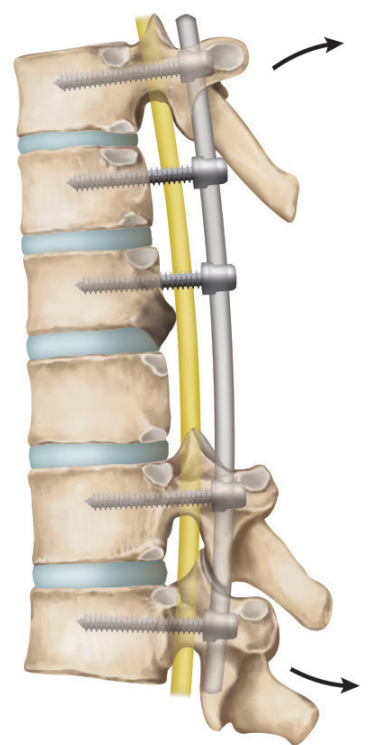

Fig. 1. Illustration of the surgical effect of posterior decompression with dekyphosis. A : Preoperative status. B : Posterior decompression with pedicle screw fixation. C: After dekyphosis procedure. 
with cord compression more than 50\% and with ossification length more than $6 \mathrm{~mm}$ were identified as 14 patients equally. Beak type OPLL was the most frequent occurred group among the three categories according to morphology and did not affect surgical outcome. The preoperative JOA score of middle thoracic lesion was significantly low compared with upper or lower thoracic spine ( $p=0.001$, Table 2$)$.

Table 2. Preoperative and postoperative neurological status related with patients' factors

\begin{tabular}{|c|c|c|c|c|c|c|c|}
\hline & Value & $\begin{array}{l}\text { Pre Op. JOA } \\
\text { score }\end{array}$ & $p$-value & $\begin{array}{l}\text { Post Op. JOA } \\
\text { score }\end{array}$ & $p$-value & $\begin{array}{c}\text { Recovery } \\
\text { rates }\end{array}$ & $p$-value \\
\hline Sex & & & 0.374 & & 0.552 & & 0.559 \\
\hline Male & 10 & $7.2 \pm 2.4$ & & $9.1 \pm 1.5$ & & $49.7 \pm 33.7$ & \\
\hline Female & 15 & $6.3 \pm 2.2$ & & $8.7 \pm 2.1$ & & $57.7 \pm 31.3$ & \\
\hline Age (years) & & & 0.475 & & 0.259 & & 0.015 \\
\hline$\geq 55$ & 10 & $7.1 \pm 2.4$ & & $8.3 \pm 2.0$ & & $35.2 \pm 30.9$ & \\
\hline$<55$ & 15 & $6.4 \pm 2.2$ & & $9.2 \pm 1.7$ & & $67.3 \pm 26.1$ & \\
\hline Symptom duration (months) & & & 0.458 & & 0.647 & & 0.339 \\
\hline$\geq 6$ & 11 & $7.1 \pm 2.7$ & & $8.6 \pm 2.2$ & & $47.1 \pm 38.0$ & \\
\hline$<6$ & 14 & $6.4 \pm 2.0$ & & $9.0 \pm 1.6$ & & $60.3 \pm 26.0$ & \\
\hline OPLL in the cervical spine & & & 0.484 & & 0.325 & & 0.583 \\
\hline Yes & 9 & $7.1 \pm 2.2$ & & $9.3 \pm 1.8$ & & $59.7 \pm 37.3$ & \\
\hline No & 16 & $6.4 \pm 2.4$ & & $8.5 \pm 1.9$ & & $51.5 \pm 29.2$ & \\
\hline OLF & & & 0.107 & & 0.218 & & 0.853 \\
\hline Yes & 14 & $6.0 \pm 1.9$ & & $8.4 \pm 1.8$ & & $53.3 \pm 28.2$ & \\
\hline No & 11 & $7.5 \pm 2.5$ & & $9.4 \pm 1.9$ & & $55.9 \pm 37.4$ & \\
\hline High signal intensity on MR image & & & 0.001 & & 0.001 & & 0.048 \\
\hline Yes & 17 & $5.8 \pm 2.1$ & & $8.1 \pm 1.7$ & & $42.5 \pm 19.8$ & \\
\hline No & 6 & $9.0 \pm 1.3$ & & $10.7 \pm 0.8$ & & $83.3 \pm 40.8$ & \\
\hline OPLL type & & & 0.090 & & 0.246 & & 0.752 \\
\hline Flat & 3 & $8.0 \pm 2.6$ & & $9.3 \pm 2.0$ & & $61.0 \pm 34.8$ & \\
\hline Beak & 17 & $7.0 \pm 2.3$ & & $9.1 \pm 1.8$ & & $56.1 \pm 34.5$ & \\
\hline Mixed & 5 & $4.8 \pm 1.1$ & & $7.6 \pm 1.8$ & & $45.0 \pm 24.0$ & \\
\hline Cord compression (\%) & & & 0.183 & & 0.395 & & 0.963 \\
\hline$\geq 50$ & 14 & $6.2 \pm 2.0$ & & $8.6 \pm 1.9$ & & $55.1 \pm 27.0$ & \\
\hline$<50$ & 11 & $7.5 \pm 2.5$ & & $9.2 \pm 1.8$ & & $55.7 \pm 38.9$ & \\
\hline Affecting level & & & 0.033 & & 0.042 & & 0.666 \\
\hline 1 & 10 & $7.8 \pm 1.8$ & & $9.7 \pm 1.4$ & & $58.3 \pm 40.5$ & \\
\hline$\geq 2$ & 15 & $5.9 \pm 2.3$ & & $8.3 \pm 1.9$ & & $51.9 \pm 25.8$ & \\
\hline Length of the OPLL (mm) & & & 0.798 & & 0.499 & & 0.554 \\
\hline$\geq 6$ & 14 & $6.6 \pm 2.2$ & & $9.1 \pm 1.7$ & & $58.0 \pm 29.7$ & \\
\hline$<6$ & 11 & $6.8 \pm 2.4$ & & $8.5 \pm 2.0$ & & $50.0 \pm 35.3$ & \\
\hline Severe cord compression level & & & 0.010 & & 0.327 & & 0.753 \\
\hline Upper & 9 & $7.2 \pm 2.3$ & & $9.1 \pm 1.8$ & & $58.8 \pm 28.7$ & \\
\hline Middle & 9 & $5.0 \pm 1.7$ & & $8.1 \pm 2.0$ & & $56.1 \pm 27.2$ & \\
\hline Lower & 7 & $8.1 \pm 1.7$ & & $9.4 \pm 1.5$ & & $46.7 \pm 43.2$ & \\
\hline
\end{tabular}

Op. : operation, JOA : Japanese Orthopedic Association, OPLL : ossification of posterior longitudinal ligament, OLF : ossification of ligamentum flavum, MR: magnetic resonance 


\section{Surgical procedures}

Surgical treatment was performed seven (28\%) anterior approaches, $13(52 \%)$ posterior approaches, and five (20\%) combined approaches. Seventeen patients $(68 \%)$ were enforced by

Table 3. Surgical outcomes related with different approaches

\begin{tabular}{lcccc}
\hline & \multicolumn{3}{c}{ Surgical approaches } & \\
\cline { 2 - 4 } & $\begin{array}{c}\text { Anterior } \\
(\mathbf{n}=\mathbf{7})\end{array}$ & $\begin{array}{c}\text { Posterior } \\
(\mathbf{n}=13)\end{array}$ & $\begin{array}{c}\text { Combined } \\
(\mathbf{n}=5)\end{array}$ & p-value \\
\hline Pre Op. JOA score & $6.7 \pm 2.6$ & $6.8 \pm 2.3$ & $6.2 \pm 2.3$ & 0.875 \\
Post Op. JOA score & $8.9 \pm 2.1$ & $9.0 \pm 1.9$ & $8.4 \pm 1.5$ & 0.837 \\
Recovery rate & $59.5 \pm 30.9$ & $59.3 \pm 33.5$ & $34.8 \pm 25.9$ & 0.316 \\
\hline
\end{tabular}

Op. : operation, JOA : Japanese Orthopedic Association

Table 4. Surgical outcomes according to instrumentation about posterior approach

\begin{tabular}{lccc} 
& \multicolumn{2}{c}{ Instrumentation } & \\
\cline { 2 - 3 } & Yes $(\mathbf{n}=\mathbf{1 1})$ & No $(\mathbf{n}=\mathbf{2})$ & \\
\hline Pre Op. JOA score & $7.4 \pm 2.1$ & $4.0 \pm 1.4$ & 0.055 \\
Post Op. JOA score & $9.5 \pm 1.4$ & $6.0 \pm 1.4$ & 0.008 \\
Recovery rate & $64.1 \pm 32.6$ & $29.0 \pm 5.66$ & 0.174 \\
\hline
\end{tabular}

Op. : operation, JOA : Japanese Orthopedic Association

Table 5. Recovery rate according to dekyphosis

\begin{tabular}{lccc}
\hline Approach & Value & Recovery rate & $\boldsymbol{p}$-value \\
\hline $\begin{array}{l}\text { Dekyphosis } \\
\text { Yes }(\mathrm{n}=7)\end{array}$ & & & \\
Posterior & 4 & & \\
Anterior & 1 & & \\
Combined & 2 & \\
No $(\mathrm{n}=18)$ & & $48.2 \pm 29.4$ & \\
Posterior & 9 & \\
Anterior & 6 & \\
Combined & 3 & \\
\hline
\end{tabular}

instrumentation. There was no significant difference of the surgical outcomes related with different surgical approaches (Table 3). However, the recovery rate tended to be low in the posterior decompression alone groups compared with instrumented group (Table 4).

Dekyphosis was acquired in seven patients. But, only four cases belonging to the posterior approach group were intended for kyphosis correction during operation. The recovery rate of these four patients was $83.3 \% \pm 23.6$ and showed excellent surgical outcome compared to other patients ( $p=0.047$, Table 5). Among four cases, two patients recovered to normal and the other two recovered partially (Table 6).

\section{Complications}

One or more complications were occurred in eight patients (32\%), including intra-operative dural tear in five patients (20\%), neurologic deterioration in four patients (16\%), and epidural hematoma required reoperation in two patients (8\%). Complication rates according to the approach were not statistically significant (Table 7). Dekyphosis did not affect the complication rates (Table 8). Dural tears were successfully sutured during surgery, and patients with motor weakness recovered after conservative treatment or epidural hematoma evacuation. There was no permanent problem related with complications. Complications did not have a significant effect on the surgical outcomes (Table 9).

\section{DISCUSSION}

Thoracic OPLL has been reported in the range of $0.8 \%$ to $1.9 \% \%^{1,16)}$. In cases of neurological deterioration, surgical treatment is often required. According to the directions of approaches, surgical methods may be divided into anterior, posterior, combined approaches, and instrumentation may be

Table 6. Patients' surgical outcomes according to degree of dekyphosis

\begin{tabular}{|c|c|c|c|c|c|c|c|c|c|}
\hline \multirow{2}{*}{ Patients No. } & \multirow{2}{*}{ Age (years) } & \multirow{2}{*}{ Sex } & \multirow{2}{*}{ Fusion level } & \multicolumn{3}{|c|}{ Cobb's angle $\left({ }^{\circ}\right)$} & \multicolumn{2}{|c|}{ JOA score } & \multirow{2}{*}{ RR (\%) } \\
\hline & & & & Pre Op. & Post Op. & Change & Pre Op. & Final F/U & \\
\hline 1 & 51 & Female & T8-11 & 11.3 & 10.1 & -1.2 & 8 & 11 & 100 \\
\hline 2 & 40 & Female & $\mathrm{T} 7-8$ & 9.2 & 8.1 & -1.1 & 8 & 11 & 100 \\
\hline 3 & 54 & Female & $\mathrm{T} 1-4$ & 9.5 & 5.3 & -4.2 & 5 & 10 & 83.3 \\
\hline 4 & 48 & Female & $\mathrm{T} 1-7$ & 30.5 & 28.5 & -2.0 & 5 & 8 & 50 \\
\hline
\end{tabular}

No. : number, Op. : operation, JOA : Japanese Orthopedic Association, F/U : follow up, RR : recovery rate 
considered depending on the patients' neurologic status and radiologic findings. Circumferential decompression that is anterior decompression with posterior approach was suggested as one of the surgical procedure ${ }^{3}$. Methods of removing the beak-type OPLL using an ultrasonic osteotome also have been introduced ${ }^{10)}$. In theoretically, OPLL is compressing in front of the spinal cord, so it is desirable to remove the cause of compression through an anterior approach. However, direct removal of OPLL has a high risk of complications such as dural tear and neurologic deficit, etc ${ }^{12,24,26}$. Diverse results of surgical techniques have been reported ${ }^{2,5,8,13-15,25)}$. Posterior approach is considered to be relatively safe, but the guidelines for surgical treatment have not yet been clarified.

We have been performed various approaches. However, posterior approach and instrumentation have been in place in 10 patients $(10 / 11,90.9 \%)$ since January 2013, and have shown good surgical outcomes. Especially, posterior decompression with dekyphosis showed excellent outcome after surgery. Koda et al. ${ }^{12)}$ suggested that dekyphosis should not be performed after posterior decompression because kyphosis correction may cause instrument failure. Hyun et al. $\left.{ }^{6}\right)$ also reported instrument failure following dekyphosis for treating adult spinal deformity. But, Zhang et al. ${ }^{27)}$ confirmed by MR image that posterior migration and complete decompression of the spinal cord was possible through posterior approach

Table 7. Complication rates related with surgical approaches

\begin{tabular}{lcccc}
\hline & Anterior & Posterior Combined & \\
& $(\mathbf{n}=\mathbf{7})$ & $(\mathbf{n}=\mathbf{1 3 )}$ & $(\mathbf{n}=5)$ & \\
\hline Complication & $3(42.9)$ & $2(15.4)$ & $3(60)$ & 0.696 \\
Dural tear & $1(14.3)$ & $1(7.7)$ & $3(60)$ & 0.088 \\
Post Op. motor weakness & $2(28.6)$ & $1(7.7)$ & $1(20)$ & 0.597 \\
Epidural hematoma & $1(14.3)$ & $1(7.7)$ & 0 & 0.378 \\
\hline
\end{tabular}

Values are presented as number (\%). Op. : operation

Table 8. Complication rates according to dekyphosis

\begin{tabular}{lccc} 
& \multicolumn{2}{c}{ Dekyphosis } & \\
\cline { 2 - 3 } & Yes $(\mathbf{n}=7)$ & No $(\mathbf{n}=18)$ & \\
\hline Complications & $3(42.9)$ & $5(27.8)$ & 0.640 \\
Dural tear & $2(28.6)$ & $3(16.7)$ & 0.597 \\
Epidural hematoma & $0(0)$ & $2(11.1)$ & 1.000 \\
Motor deterioration & $1(14.3)$ & $3(16.7)$ & 1.000 \\
\hline
\end{tabular}

Values are presented as number (\%) with kyphosis correction. We performed posterior decompression with dekyphosis in four patients, and experienced full recovery in two patients (patients 1 and 2) and partial recovery in two patients (patients 3 and 4) (Table 6). We thought that the preoperative JOA score was as high as 8 points, which might be a contributing factor that could complete recovery in two patients. The remaining two patients had a relatively low preoperative JOA score of 5 points, but one patient (patient 3) had a high recovery rate of $83.3 \%$. One (patient 3 ) had a greater angle of kyphosis correction compared to the other patient (patient 4), and the spinal cord was effectively decompressed, resulting in a good clinical outcome (Figs. 2 and 3). Thoracic spine has physiological kyphosis, and OPLL compress the spinal cord anteriorly. In the posterior approach, direct OPLL removal is difficult, but even more effective indirect decompression can be performed by dorsally shifting the spinal cord through dekyphosis without removing it directly. In this study, instrument failure did not occur. Therefore, posterior decompression with dekyphosis seemed to be a way to maximize the purpose of decompression by lowering the complication of the anterior approach.

Several institutions have reported that only posterior decompression may worsen the cord compression by progressive thoracic kyphosis ${ }^{1,12,16,19)}$. In our experience, recovery rates tended to lower in only posterior decompression group. We could identify that the compression of the spinal cord became worse as shown Fig. 2 after laminectomy alone. There is a lim-

Table 9. Recovery rate according to complication

\begin{tabular}{lrcc}
\hline & Value & Recovery rate & $\boldsymbol{p}$-value \\
\hline Complication & 8 & $52.6 \pm 36.0$ & 0.857 \\
Yes & 17 & $55.4 \pm 30.8$ & \\
No & & & 0.698 \\
Dural tear & 5 & $48.2 \pm 40.0$ & \\
$\quad$ Yes & 20 & $56.0 \pm 30.5$ & \\
No & & & 0.737 \\
Post Op. motor weakness & 4 & $59.2 \pm 28.4$ & \\
$\quad$ Yes & 21 & $53.6 \pm 33.0$ & \\
No & & & 0.632 \\
Epidural hematoma & 2 & $71.5 \pm 40.3$ & \\
Yes & 23 & $53.0 \pm 31.7$ & \\
No & & & \\
\hline
\end{tabular}

Op. : operation 
it to generalize the low recovery rate of the posterior decompression alone group from our study. Because only two patients included in this group, and the low preoperative JOA score might inhibit recovery.

We reported that patients with single-level OPLL had a higher preoperative and postoperative JOA scores than the other patients. Hu et al. ${ }^{3)}$ reported 26 patients who underwent circumferential decompression, the recovery rate was lower as the level of OPLL was increased. We applied various surgical procedures for multilevel OPLL, and the surgical outcome of multilevel OPLL was not statistically lower than that of singelevel OPLL. The thoracic spinal cord is the watershed area of the spinal circulation, which may have affected neurologic status due to a decrease in blood supply in the presence of multilevel lesions. However, if appropriate surgery is performed according to the patients' status, satisfactory results will be obtained as in this study.

Clinically, old age ( $\geq 55$ years) was related to poor surgical outcome. Patients included in the old age group had a low recovery rate although the preoperative neurologic status was not bad compared to the young age group. Xu et al. ${ }^{24)}$ noticed that complication rates of surgical treatment for thoracic OPLL and patients' age were independent different to cervical OPLL. We suggest that degradation of functional recovery capacity play a major role in poor clinical course. The data of the current study indicate that patient's age can substantially in-
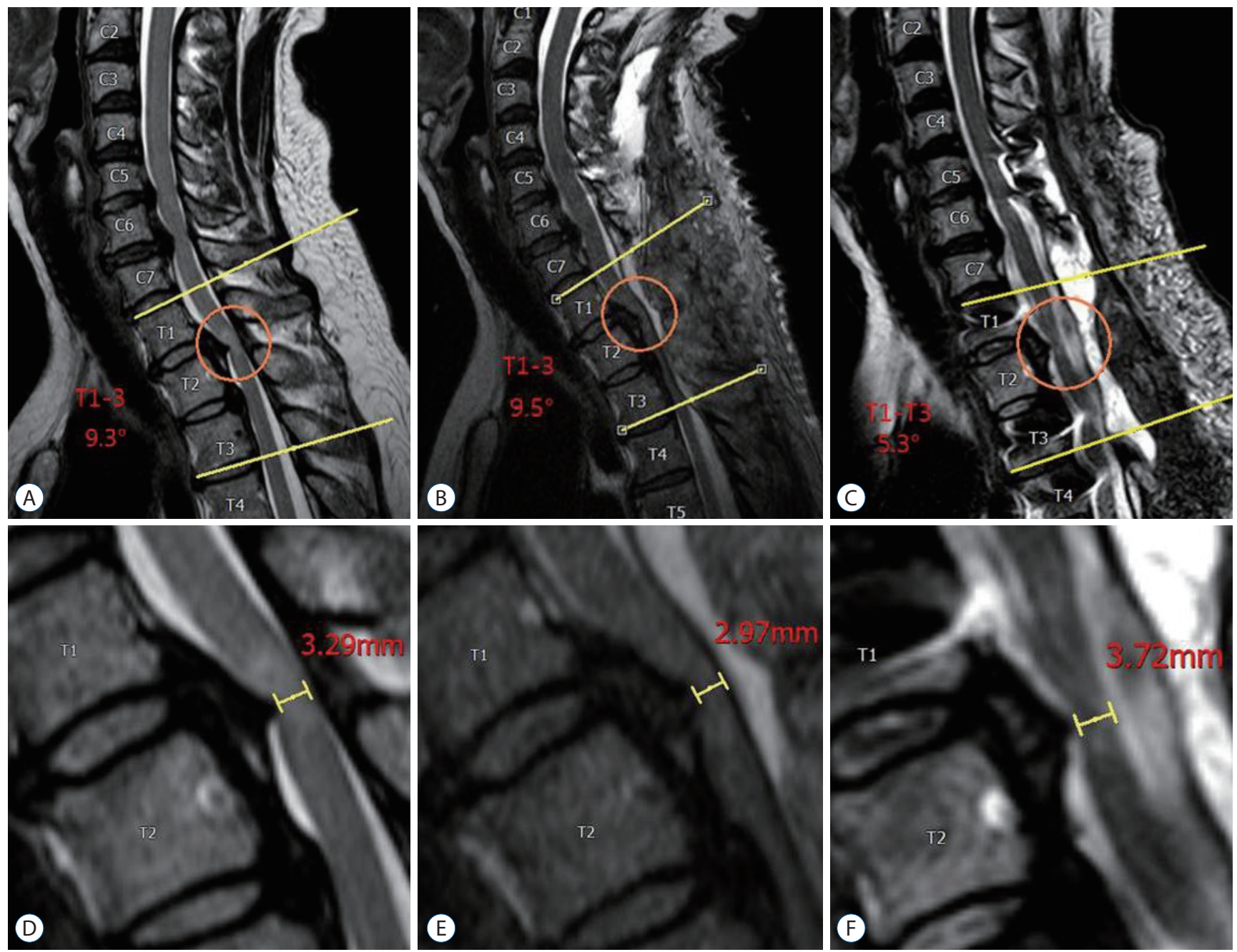

Fig. 2. A 54-year-old female (patient No. 3) presented with lower extremities weakness. She underwent decompressive laminectomies without instrumentation at the T1-3 levels in another hospital and then increased the Cobb's angle from $9.3^{\circ}(A)$ to $9.5^{\circ}(B)$, resulting in progression of compressive myelopathy (D and E). We performed posterior instrumented fusion with dekyphosis from T1 to T4 levels (C). After revision surgery, we obtained an effective decompression of the spinal cord ( $\mathrm{F})$, and her neurological status was significantly improved (recovery rate=83.3\%). 
fluence the surgical outcome of thoracic OPLL. It is necessary to inform the patients and their caregivers about the prognosis following surgery. Surgeons should agonize to increase the recovery capacity of elderly patients.

In radiological exam, intramedullary signal change on preoperative MR image affected severe preoperative, postoperative neurologic deficits and poor surgical outcome. On the other hand, several factors (ossification length, $\geq 6 \mathrm{~mm}$ vs. $<6$ $\mathrm{mm}$; degree of cord compression, $\geq 50 \%$ vs. $<50 \%$; morphologic type, flat vs. beak vs. mixed) did not affect surgical outcomes. Several articles have reported that the beak-type OPLL promotes a stressful situation in the spinal cord, leading to poor surgical outcome ${ }^{7,19)}$. However, in this study, the surgical outcome of patients with beak type OPLL was not poor. Many authors thought that intramedullary high signal intensity in MR image is evidence of pathologic damage to the spinal cord $^{11)}$. The pathology is considered range from acute edema
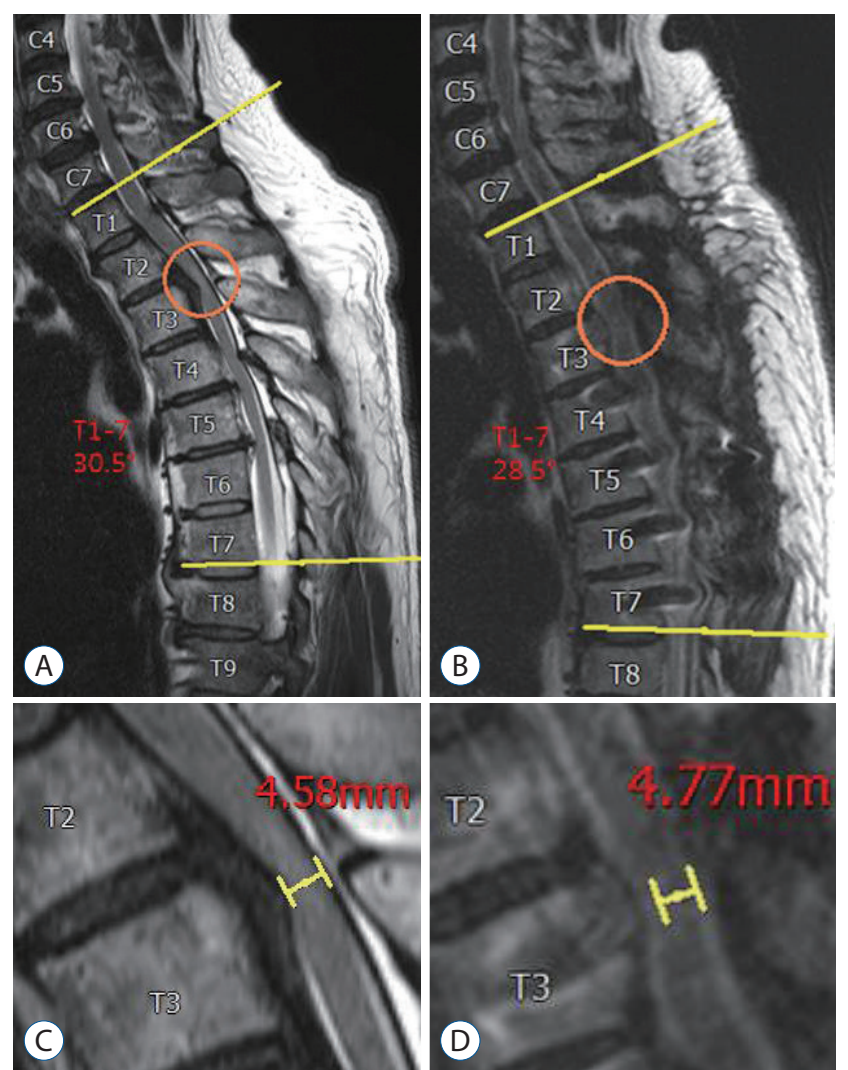

Fig. 3. A 48-year-old female (patient No. 4) presented with lower extremities weakness. She underwent posterior decompression and instrumented fusion with dekyphosis from T1 to T7 levels (A and B). Postoperative anterior-posterior diameter of the spinal cord became widening ( $C$ and $D)$, and her neurological status was substantially improved (recovery rate=50\%). to chronic myelomalacia ${ }^{1,9,22)}$. In Thoracic OPLL, signal change of spinal cord is the result of accumulation of microtrauma due to persistent mechanical stress from ossified lesions. It reduces the reversible resilience of the spinal cord and results in poor surgical outcome. As a result, the shape or degree of compression of the OPLL is not critical, but the presence of intramedullary high signal intensity in MR image is considered to be the most important radiologic factor for surgical outcome.

We did not find out a significant association between the occurrence of complications and the surgical outcome. Hu et al. ${ }^{3)}$ reported that cerebrospinal fluid leakage by dural tear with circumferential decompression of multilevel thoracic OPLL did not affect the surgical outcome. Xu et al. ${ }^{24)}$ noted that the complication rates tended to be negatively correlated with the postoperative JOA score. We used intraoperative neuromonitoring during every surgery. We irrigated operating field by warm saline and raised mean arterial pressure when intraoperative neuromonitoring was deteriorated. In the thoracic spine, OPLL itself may cause additional neurological impairment after laminectomy alone with increased compression of the spinal cord. Therefore, we subsequently performed laminectomy after installing a rod to prevent additional ventral compression of the spinal cord during surgery. We underwent suture in case of dural tear during surgical procedure and occasionally reinforced with fat tissue to minimize the cerebrospinal fluid leakage. MR images were obtained when postoperative motor paralysis occurred, hematoma evacuation was performed on two cases with epidural hematoma, and all of them recovered from neurological deteriorations. Complications are capable of overcoming to cope with the general management, and thus complication does not affect to have a significant effect on the poor surgical outcome. In other paper, they reported that if complications were treated properly, most complications can be recovered with satisfactory outcomes ${ }^{26)}$.

There are some limitations of present study, including it retrospective nature, small number of patients, and various surgical procedures, all of which may make it difficult to appeal statically significant conclusions. Nevertheless, this was a single institution study of patients with thoracic OPLL, a rare disease, who were treated surgically. We desire that the surgical results may afford basic data in support of the predictors for treating thoracic OPLL. 


\section{CONCLUSION}

Posterior approach with dekyphosis is a relatively safe and effective procedure for the management of thoracic OPLL which can be a recommendable surgical option for favorable results. Our study showed that old age ( $\geq 55$ years) and presence of intramedullary high signal intensity in preoperative MR image in the thoracic spine were associated with poor surgical outcomes. Considering these factors, surgeons should be aware of the importance of planning in appropriate surgical treatments for thoracic OPLL.

\section{CONFLICTS OF INTEREST}

No potential conflict of interest relevant to this article was reported.

\section{INFORMED CONSENT}

This type of study does not require informed consent.

\section{AUTHOR CONTRIBUTIONS}

\author{
Conceptualization : $\mathrm{SJH}$ \\ Data curation : SYK \\ Formal analysis : SYK \\ Methodology : SJH \\ Project administration : SYK \\ Visualization: SYK \\ Writing - original draft : SYK \\ Writing - review \& editing : $\mathrm{SJH}$
}

\section{References}

1. Ando K, Imagama S, Kobayashi K, Hida T, Ito K, Tsushima M, et al. : Comparative study of surgical treatment and nonsurgical follow up for thoracic ossification of the posterior longitudinal ligament: radiological and clinical evaluation. Spine (Phila Pa 1976) 42 : 407-410, 2017

2. Fujimura $Y$, Nishi $Y$, Nakamura $M$, Watanabe $M$, Matsumoto $M$ : Myelopathy secondary to ossification of the posterior longitudinal ligament of the thoracic spine treated by anterior decompression and bony fusion.
Spinal Cord 35 : 777-784, 1997

3. Hu P, Yu M, Liu $X$, Liu Z, Jiang $L$ : A circumferential decompressionbased surgical strategy for multilevel ossification of thoracic posterior longitudinal ligament. Spine J 15 : 2484-2492, 2015

4. Hyun SJ, Kim JS, Hong SC : Late occurrence of cervicothoracic ossification of posterior longitudinal ligaments in a surgically treated thoracic OPLL patient. J Korean Neurosurg Soc 47 : 55-57, 2010

5. Hyun SJ, Kim YJ, Cheh G, Yoon SH, Rhim SC : Free hand pedicle screw placement in the thoracic spine without any radiographic guidance : technical note, a cadaveric study. J Korean Neurosurg Soc 51 : 6670, 2012

6. Hyun SJ, Lee BH, Park JH, Kim KJ, Jahng TA, Kim HJ : Proximal junctional kyphosis and proximal junctional failure following adult spinal deformity surgery. Korean J Spine 14 : 126-132, 2017

7. Imagama S, Ando K, Ito Z, Kobayashi K, Hida T, Ito K, et al. : Risk factors for ineffectiveness of posterior decompression and dekyphotic corrective fusion with instrumentation for beak-type thoracic ossification of the posterior longitudinal ligament: a single institute study. Neurosurgery $80: 800-808,2017$

8. Kawahara N, Tomita K, Murakami H, Hato T, Demura S, Sekino Y, et al. : Circumspinal decompression with dekyphosis stabilization for thoracic myelopathy due to ossification of the posterior longitudinal ligament. Spine (Phila Pa 1976) 33 : 39-46, 2008

9. Kim B, Yoon DH, Shin HC, Kim KN, Yi S, Shin DA, et al. : Surgical outcome and prognostic factors of anterior decompression and fusion for cervical compressive myelopathy due to ossification of the posterior longitudinal ligament. Spine J 15 : 875-884, 2015

10. Kim CH, Renaldo N, Chung CK, Lee HS : Use of an ultrasonic osteotome for direct removal of beak-type ossification of posterior longitudinal ligament in the thoracic spine. J Korean Neurosurg Soc 58 : 571-577, 2015

11. Kim JK, Ryu HS, Moon BJ, Lee JK : Clinical outcomes and prognostic factors in patients with myelopathy caused by thoracic ossification of the ligamentum flavum. Neurospine 15 : 269-276, 2018

12. Koda M, Furuya T, Okawa A, Inada T, Kamiya K, Ota M, et al. : Midto long-term outcomes of posterior decompression with instrumented fusion for thoracic ossification of the posterior longitudinal ligament. J Clin Neurosci 27 : 87-90, 2016

13. Komagata M, Inahata Y, Nishiyama M, Endo K, Tanaka H, Kobayashi H : Treatment of myelopathy due to cervicothoracic OPLL via open door laminoplasty. J Spinal Disord Tech 20 : 342-346, 2007

14. Lee BH, Hyun SJ, Park JH, Kim KJ : Single stage posterior approach for total resection of presacral giant schwannoma: a technical case report. Korean J Spine 14 : 89-92, 2017

15. Matsumoto M, Chiba K, Toyama Y, Takeshita K, Seichi A, Nakamura K, et al. : Surgical results and related factors for ossification of posterior longitudinal ligament of the thoracic spine: a multi-institutional retrospective study. Spine (Phila Pa 1976) 33 : 1034-1041, 2008

16. Matsumoto M, Toyama Y, Chikuda H, Takeshita K, Kato T, Shindo S, et al. : Outcomes of fusion surgery for ossification of the posterior longitudinal ligament of the thoracic spine: a multicenter retrospective survey: 
clinical article. J Neurosurg Spine 15 : 380-385, 2011

17. Matsunaga $S$ : Updates on ossification of posterior longitudinal ligament. Epidemiology and pathogenesis of OPLL. Clin Calcium 19 : 1415-1420, 2009

18. Matsuyama Y, Sakai Y, Katayama Y, Imagama S, Ito Z, Wakao N, et al. : Indirect posterior decompression with corrective fusion for ossification of the posterior longitudinal ligament of the thoracic spine: is it possible to predict the surgical results? Eur Spine J 18 : 943-948, 2009

19. Matsuyama Y, Yoshihara H, Tsuji T, Sakai Y, Yukawa Y, Nakamura H, et al. : Surgical outcome of ossification of the posterior longitudinal ligament (OPLL) of the thoracic spine: implication of the type of ossification and surgical options. J Spinal Disord Tech 18 : 492-497; discussion 498, 2005

20. Mori K, Imai S, Kasahara T, Nishizawa K, Mimura T, Matsusue $Y$ : Prevalence, distribution, and morphology of thoracic ossification of the posterior longitudinal ligament in Japanese: results of CT-based crosssectional study. Spine (Phila Pa 1976) 39 : 394-399, 2014

21. Ohtsuka K, Terayama K, Yanagihara M, Wada K, Kasuga K, Machida T, et al. : A radiological population study on the ossification of the posterior longitudinal ligament in the spine. Arch Orthop Trauma Surg $106: 89-93,1987$

22. Shimomura T, Sumi M, Nishida K, Maeno K, Tadokoro K, Miyamoto H, et al. : Prognostic factors for deterioration of patients with cervical spondylotic myelopathy after nonsurgical treatment. Spine (Phila Pa 1976) 32 : 2474-2479, 2007

23. Wu JC, Chen YC, Huang WC : Ossification of the posterior longitudinal ligament in cervical spine: prevalence, management, and prognosis. Neurospine $15: 33-41,2018$

24. Xu N, Yu M, Liu X, Sun C, Chen Z, Liu Z : A systematic review of complications in thoracic spine surgery for ossification of the posterior longitudinal ligament. Eur Spine J 26 : 1803-1809, 2017

25. Yamazaki M, Mochizuki M, Ikeda Y, Sodeyama T, Okawa A, Koda M, et al. : Clinical results of surgery for thoracic myelopathy caused by ossification of the posterior longitudinal ligament: operative indication of posterior decompression with instrumented fusion. Spine (Phila Pa 1976) $31:$ 1452-1460, 2006

26. Yang B, Wang Y, He X, Li H : Treatment for thoracic ossification of posterior longitudinal ligament with posterior circumferential decompression: complications and managements. J Orthop Surg Res 11 : 153, 2016

27. Zhang HQ, Chen LQ, Liu SH, Zhao D, Guo CF : Posterior decompression with kyphosis correction for thoracic myelopathy due to ossification of the ligamentum flavum and ossification of the posterior longitudinal ligament at the same level. J Neurosurg Spine 13 : 116-122, 2010 